\title{
Optimum Extraction of Bioactive Alkaloid Compounds from Rhizome Coptidis (Coptis Chinensis Franch.) Using Response Surface Methodology
}

\author{
Hui TENG ${ }^{1}$ and Yonghee $\mathrm{CHOI} *{ }^{1,2}$ \\ ${ }^{1}$ School of Food Science and Bio-Technology, Kyungpook National University, 1370-Sankyunk Dong, \\ Puk Gu, Daegu 702-701, Korea \\ ${ }^{2}$ Food and Bio-Industry Research Institute, Kyungpook National University, 1370-Sankyunk Dong, \\ Puk Gu, Daegu 702-701, Korea
}

\begin{abstract}
Rhizome coptidis is a common traditional herb in China with an abundant alkaloid content that has remedial effects on various chronic diseases. In this study, an acid-assisted extraction method was developed for the extraction of the alkaloids from rhizome coptidis, and response surface methodology was applied to optimize the extraction process conditions. Individual alkaloids were isolated and identified using high performance liquid chromatography with an ultraviolet detector (HPLC-UV). Five different acids were tested, and the highest total alkaloid content including berberine and palmatine content were detected in phosphoric acid extracts. A box-Behnken design with 3 levels and 3 variables was employed and optimal conditions were obtained as follows: $0.34 \%$ phosphoric acid concentration, $5.00 \mathrm{~h}$ extraction time, and $51.45 \mathrm{~mL} / \mathrm{g}$ solvent to sample ratio. A verification experiment was carried out under the estimated optimal conditions, and a good correlation between estimated and observed values indicated that the fitted model was valid and the prediction was successful. Compared with other extraction methods, acid-assisted extraction is simpler, safer and more economic with a high alkaloid yield which could be potentially used as alternative choice for industrial production.
\end{abstract}

\section{Introduction}

Rhizome coptidis (Coptidis chinensis Franch.), which is known as Huang lian in Chinese, is derived from the roots of several natural plants from the family Ranunculaceae. It is commonly used as a traditional Chinese herb and has been widely used to treat dysentery and arrhythmia for two thousand years 
[1]. The main constituents contained in rhizome coptidis are alkaloids, and seven types of alkaloids have been successfully isolated and identified as quaternary ammonium hydroxides [2]. Among them, berberine and palmatine are regarded as the major alkaloids amounting to $50 \%$ of the total alkaloid content [3]. In recent decades, research attention has been given to phytochemicals especially with regard to traditional Chinese herbs, and many bioactive compounds have been isolated from phytochemicals including alkaloids, phenolics, terpenes, etc., which have been proven to be effective for various chronic diseases with few side effects [4]. Berberine has a great variety of pharmacological uses such as anti-bacterial, anti-plasmodial, and antidiarrheal and cardiovascular protective effects [5-7], and now is widely used in both China and in other countries around the world.

Although great progress has been made with regard to the pharmaceutical effects of rhizome coptidis, little attention has been paid to improving the alkaloids yields from rhizome coptidis. Until now, various extraction techniques have been applied to the extraction of alkaloids, such as conventional heating reflux, and soxhlet extraction as well as advanced super critical $\mathrm{CO}_{2}$ extraction and ultrasonic-assisted and microwave-assisted extraction techniques [2, 8-10]. However, these techniques can only achieve a low yield and a more appropriate extraction method for rhizome coptidis with a high output of alkaloid yield is required, not only with the purpose of the rational use of the natural source, but also for large scale production in industry. Acid-assisted extraction is another method for alkaloid extraction using a low concentration acid solution to combine with the free base organic alkaloids thus transformed them into inorganic alkaloid salts with improved solubility.However, little research canbe found on using acid-assisted extraction or its optimization method to improve the yield of alkaloids from rhizome coptidis.

In the present study, the alkaloids contained in rhizome coptidis were extracted with a low concentration acid solution, and the effects of different acid species, extraction time, acid concentration, and solvent to sample ratio were investigated. The berberine and palmatine contents were separated and quantified using a high efficient liquid chromatography-ultraviolet detector (HPLC-UV). Response surface plots and contour plots were constructed based on a three variables, three levels box-Behnken design (BBD), and the best combination of extraction conditions was optimized using overlapped contour plots. In addition, the validity of the prediction was verified by carrying out an experiment under the estimated conditions, and other conventional approaches were also employed for comparison of the extraction efficiencies.

\section{Experimental}

\subsection{Chemicals}

Berberine chloride, palmatine chloride (purity $>98 \%$, w/w), and potassium dihydrogen phosphate were purchased from Sigma chemical Co., Ltd. (Sigma Chemical Co., St. Louis, MO, USA). Ethanol (95\%) and acetonitrile HPLC grade and five different types of acid solutions that included hydrochloric acid (37.2\%), phosphoric acid (85.0\%), nitric acid (70.98\%), sulfuric acid (95.6\%), and acetic acid 
(36.0\%) were purchased from the Duksan Pure Chemical Company (Ansan, Korea).

\subsection{Preparation of the rhizome coptidis sample}

The dried rhizome coptidis, originally cultivated in Sichuang province in China, was purchased and authenticated under the guidance of the Pharmacopeia of China (2005 version). The dried rhizome coptidis was grounded into powder in an electric grinder and passed through a 40 mesh sieve with an aperture size of $250 \mu \mathrm{m}$. The powdered sample was packed in a polyethylene zip pail and stored in a freezer at $-18^{\circ} \mathrm{C}$ during the experiments.

\subsection{Acid-assisted extraction process}

Firstly, the effect of different acids was investigated including four types of inorganic acids (hydrochloric acid, phosphoric acid, nitric acid, and sulfuric acid) and an organic acid (acetic acid). The concentration of each acid was diluted to an equal level $(0.5 \%)$ when testing the different acids. The effects of different extraction times $(1 \mathrm{~h}-8 \mathrm{~h})$, acid concentrations $(0 \%-1.0 \%)$, and solvent to sample ratios $(20 \mathrm{~mL} / \mathrm{g}-60 \mathrm{~mL} / \mathrm{g})$ on the extraction of the alkaloids from rhizome coptidis were also examined based on the single factor experiment principal. The extraction procedure was as follows: one gram of accurately weighted rhizome coptidis powder was mixed with an acid solution in a $250 \mathrm{~mL}$ flat bottom flask, and then the mixture was stirred to disperse the sample powder well. This was then macerated at room temperature $\left(25^{\circ} \mathrm{C}\right)$ for the required extraction time. After extraction, the the mixture was filtered and the filtrates were immediately collected in volumetric flask and diluted to a final volume of $100 \mathrm{~mL}$. Extracts of $2 \mathrm{~mL}$ were injected using a $0.45 \mu \mathrm{m}$ PTFE syringe filter for alkaloid analysis.

\subsection{Soxhlet extraction process}

One gram of the powder sample was accurately weighed, transferred into a cellulose extraction thimble, and placed in a soxhlet chamber. One-hundred milliliters of $50 \%$ ethanol solution was added into a $500 \mathrm{~mL}$ round bottom flask, and heated to $70{ }^{\circ} \mathrm{C}$. The extraction was carried out for $4 \mathrm{~h}$ until the extracts in the siphon pipe became colorless, then the extracts were evaporated under vacuum and redissolved in $50 \%$ ethanol and made up to $100 \mathrm{~mL}$ for analysis. Soxhlet extracts of $2 \mathrm{~mL}$ were injected using a $0.45 \mu \mathrm{m}$ PTFE syringe filter for alkaloid analysis as well.

\subsection{Heating reflux extraction process}

One gram of a precisely weighted sample was placed in a $250 \mathrm{~mL}$ flat bottom flask, soaked with 35 $\mathrm{mL}$ of a $50 \%$ aqueous ethanol solvent for $1 \mathrm{~h}$, and then extracted for $4 \mathrm{~h}$ at a temperature of $70{ }^{\circ} \mathrm{C}$ in a heated water bath. After extraction, the flask was removed from the water bath and the extract was immediately filtered through Whatman No.5 filter paper under vacuum. The solution was collected in a volumetric flask and the final volume was made up $100 \mathrm{~mL}$. Heated reflux extracts of $2 \mathrm{~mL}$ were injected using a $0.45 \mu \mathrm{m}$ PTFE syringe filter for alkaloid analysis.

\subsection{Determination of the total alkaloid content}

The total alkaloid content of the rhizome coptidis extract was determined according to the method as described by $\mathrm{Xu}$ et al. [3] using a 96-well ultraviolet-visible spectrophotometer. After scanning at a 
maximal wave length, $345 \mathrm{~nm}$ was selected as the detective wavelength with minimal impurity interference. Thus, the total alkaloid content contained in rhizome coptidis was determined by using $1 \mathrm{~mL}$ of an appropriately diluted sample (100 times diluted), and the absorption values were recorded at $345 \mathrm{~nm}$. Pure ethanol was used as a blank and berberine chloride was used as a reference for the calibration curve $\left(\mathrm{R}^{2}=0.9997\right)$. The results were expressed as $\mathrm{mg}$ of berberine chloride equivalent/g (mg BCE/g) of dry rhizome coptidis.

\subsection{HPLC analysis of the berberine and palmatine content}

The alkaloid constituents of berberine and palmatine extracted from rhizome coptidis were analyzed using a high performance liquid chromatograph (Waters, Milford, MA, USA) with an ultraviolet-visible detector (Jasco, Japan) according to the method described by Ye et al. [11]. The separation was carried out using a C18 reverse-phase column (A XTerra, $250 \mathrm{~mm} \times 4.6 \mathrm{~mm}$ ). The elution system consisted of acetonitrile (A) and $25 \mathrm{mmol} / \mathrm{L}$ potassium dihydrogen phosphate in distilled water (B) at a ratio of 25:75 with a flow rate of $1.0 \mathrm{~mL} / \mathrm{min}$. The detecting wavelength and retention time were set at $345 \mathrm{~nm}$ and 30 min, respectively.

Berberine chloride and palmatine chloride standard stock solutions were prepared by dissolving accurately weighted standards in $10 \mathrm{~mL}$ of pure ethanol to an initial concentration of $50 \mu \mathrm{g} / \mathrm{mL}$ for berberine chloride and $30 \mu \mathrm{g} / \mathrm{mL}$ for palmatine chloride. Standard working solutions used for the calibration were prepared by diluting the above standard solutions with ethanol to the desired concentrations. Good linearity of the calibration curves for the berberine chloride and palmatine chloride standards were achieved with correlation coefficients of 1.000 and 0.9970 , respectively. Results were expressed as mg berberine chloride equivalent/g (mg BCE/g) and mg palmatine equivalent/g (mg PCE/g) of dry rhizome coptidis.

\subsection{Experimental design}

A box-Behnken design (BBD) is an independent quadratic design in that it does not contain an embedded factorial or fractional factorial design. In this design the treatment combinations are at the midpoints of ethe dges of the process space and at the center. A BBD with three levels and three variables was generated by the built-in package (ADX module) of the SAS system (version 9.3, SAS Institute, Cary, $\mathrm{NC}$ ) to determine the best combination of process variables for the extraction of alkaloids from rhizome coptidis. The design matrices consisted of 3 central points and another 12 points that were located on a hypersphere equidistant from the central point, leading to 15 sets of experimental runs. The process variables $X i$ were coded as $x i$ according to the equation below:

$$
x_{i}=\left(X_{i}-\bar{X}_{i}\right) / \Delta X_{i}
$$

where $x_{i}$ is the coded level and $X_{i}$ is the natural level for the independent variable; $\bar{X}_{i}$ is the mean for the natural level of the independent variables, and $\Delta X_{i}$ is the step change value. The BBD matrices and the process variables in the coded and natural levels are presented in Table1. The alkaloid content, berberine content, and palmatine content were considered as the dependent responses. 
Regression analysis was performed according to the experimental data and was fitted into an empiric second order polynomial model presented in the following equation:

$$
Y=\beta_{0}+\sum_{i=1}^{k} \beta_{i} x_{i}+\sum_{i=1}^{k} \beta_{i i} x_{i}^{2}+\sum_{1 \leq i \leq j}^{k} \beta_{i j} x_{i} x_{j}+\varepsilon
$$

where $Y$ represents the independent responses; $\beta_{0}, \beta_{i}, \beta_{i i}$ and $\beta_{i j}$ represent the regression coefficients of the process variables for the intercept, linear, quadratic, and cross product terms, respectively. The statistical significance of the coefficients in the regression equation was checked by analysis of variance (ANOVA). The fitness of the polynomial model equation to the responses was evaluated by the coefficient of $\mathrm{R}$ square, adjective $\mathrm{R}$ square and predictive $\mathrm{R}$ square as well as the lack of fit using the F-test.

\subsection{Statistical analysis}

All analytical experiments were performed in triplicate. Experimental data obtained from the BBD matrices were analyzed by the analysis of variance $(p<0.05)$ with the SAS system. The bar diagrams were generated by Microsoft Excel (Microsoft Office 2010 for Windows) and the significance of the different variable levels were analyzed by Duncan's multiple range tests under the SAS system. Three dimensional response surface plots, and 2 dimensional contour plots were generated using Statistica 8.0 (Statsoft Inc., USA).

\section{Results and Discussion}

\subsection{Effects of acid species on the extraction of alkaloids from rhizome coptidis}

Five different acids were tested for the extraction of alkaloids from rhizome coptidis and the results are shown in Figure 1. In general, the organic acid (acetic acid) had medium extraction strength when compared with the inorganic acids for alkaloids extraction. It was found that the berberine content was quite low when extracted by $0.5 \%$ hydrochloric acid, and a similar result was reported by Lee et al. [12], who explained this phenomenon as quaternary alkaloids having poor solubility in the hydrochloride salt form. Meanwhile, $0.5 \%$ sulfuric acid was able to extract the best total alkaloid content but the berberine and palmatine contents were low when using sulfuric acid. Compared with the other acids, phosphoric acid had a better effect on the extraction of total alkaloid content (TAC), berberine content (BC), and palmatine content (PC). In most circumstances [3, 13, 14], sulfuric acid has been chosen as the best medium for the extraction of alkaloids from rhizome coptidis, because the alkaloids in the sulfate form have a good solubility in water. However, the present study revealed that phosphoric acid exhibited better extraction ability than sulfuric acid for the berberine and palmatine contents, suggesting that phosphoric acid should be more suitable for the extraction of alkaloids from rhizome coptidis.

\subsection{Effect of acid concentration on the extraction of alkaloids from rhizome coptidis}

The effects of different phosphoric acid concentrations were investigated after the good extraction efficiency of phosphoric acid was confirmed in section 3.1. As shown in Figure 2, a significant increase in alkaloid output was found when the phosphoric acid concentration was increased from $0 \%$ to $0.25 \%$, which confirmed that the efficiency of the extraction of alkaloids could be greatly improved by adding a 


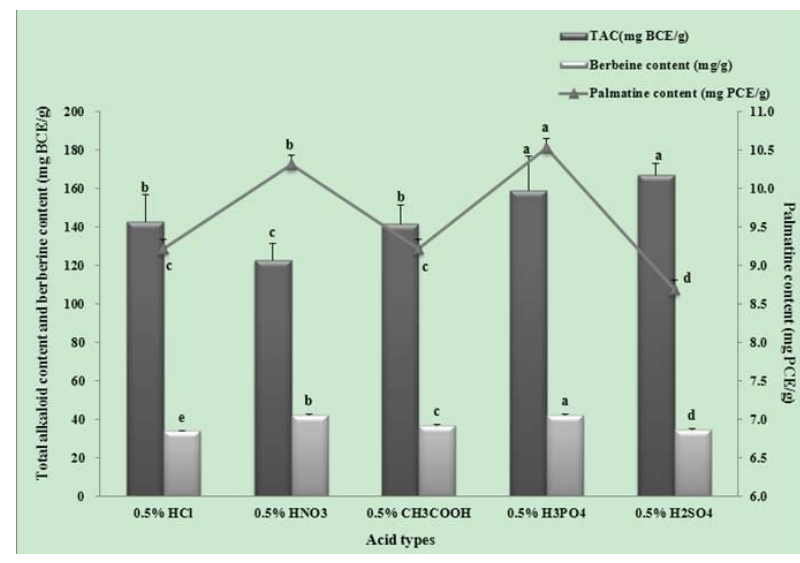

Figure 1. The effect of acid types on alkaloid extraction from rhizoma coptidis. Total alkaloid and berberine contents are shown in the primary axis as bars, while the palmatine content is shown in the secondary axis as a line. The vertical error bars represent standard deviations $(\mathrm{n}=3)$. Different letters above the bars indicate significance $(p<0.05)$, while the same letters show insignificant effects.

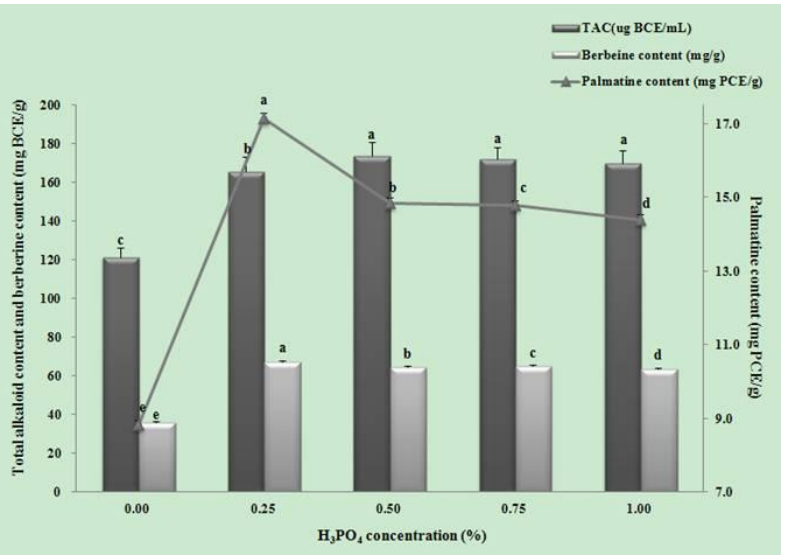

Figure 2. The effect of phosphoric acid concentration on alkaloid extraction from rhizoma coptidis. Total alkaloid and berberine contents are shown in the primary axis as bars, while the palmatine content is shown in the secondary axis as a line. The vertical error bars represent standard deviations $(\mathrm{n}=3)$. Different letters above the bars indicate significance $(\mathrm{p}<0.05)$, while the same letters show insignificant effects.

small amount of phosphoric acid. The BC and PC had the highest yields of $17.15 \mathrm{mg} \mathrm{BCE} / \mathrm{g}$ and $6.74 \mathrm{mg}$ $\mathrm{PCE} / \mathrm{g}$, respectively, with $0.25 \%$ phosphoric acid. Besides, the TAC increased with an increase in the phosphoric acid concentration reaching the highest yield of $173.87 \mathrm{mg} \mathrm{BCE} / \mathrm{g}$ at $0.5 \%$ phosphoric acid. However, little difference was observed between the phosphoric acid concentrations of $0.5 \%$ and $1.0 \%$ according to the Duncan test results (Figure 2). Therefore, a phosphoric acid concentration of around $0.25 \%$ was determined to be optimal for the extraction of alkaloids from rhizome coptidis.

\subsection{Effect of the extraction time on alkaloid extraction from rhizome coptidis}

The effect of the extraction time ranging from $1 \mathrm{~h}$ to $8 \mathrm{~h}$ on alkaloid extraction from rhizome coptidis was determined checked and the results are shown in Figure 3. In general, the extraction time had a more important role in the extraction of $\mathrm{BC}$ and PC, but gave less impact on the TAC judged by the significance based on the Duncan test. TAC, BC, and PC increased with increasing extraction time from $1 \mathrm{~h}$ to $4 \mathrm{~h}$ and reached the highest values of $177 \mathrm{mg} \mathrm{BCE} / \mathrm{g}, 66.10 \mathrm{mg} \mathrm{BCE} / \mathrm{g}$, and $15.08 \mathrm{mg} \mathrm{PCE} / \mathrm{g}$, respectively, at $4 \mathrm{~h}$. No significant effect was observed for TAC when the extraction time was increased from $4 \mathrm{~h}$ to $8 \mathrm{~h}$. However, a significant decline in the BC (dropped to $61.33 \mathrm{mg} \mathrm{BCE} / \mathrm{g}$ ) and PC extractions (dropped to $14.02 \mathrm{mg}$ PCE/g) occurred when the extraction time was increased from $4 \mathrm{~h}$ to $8 \mathrm{~h}$. Thus, an extraction time of $4 \mathrm{~h}$ was selected as the central point for the BBD. 


\subsection{Effect of the solvent to sample ratio on alkaloid extraction from rhizome coptidis}

Solvent to sample ratio is another factor that may have a potentially significant effect on the alkaloid extraction process from rhizome coptidis and should be considered. Figure 4 shows the effect of different solvent to sample ratios ranging from 20 to $60 \mathrm{~mL} / \mathrm{g}$. It was found that there was no significant difference for TAC when changing the solvent to sample ratio from 30 to $60 \mathrm{~mL} / \mathrm{g}$. However, the $\mathrm{BC}$ and PC yields increased significantly when the solvent to sample ratio increased from 20 to $50 \mathrm{~mL} / \mathrm{g}$ and attained the highest yield of $64.59 \mathrm{mg} \mathrm{BCE} / \mathrm{g}$ and $14.86 \mathrm{mg} \mathrm{PCE} / \mathrm{g}$ at $50 \mathrm{~mL} / \mathrm{g}$, respectively, according to the results of the Duncan test (in Figure .4).

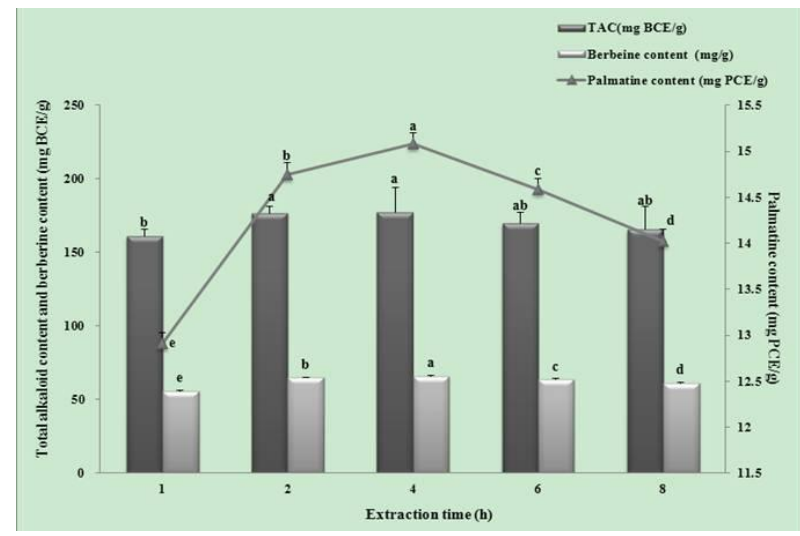

Figure 3. The effect of extraction time on alkaloid extraction from rhizoma coptidis.

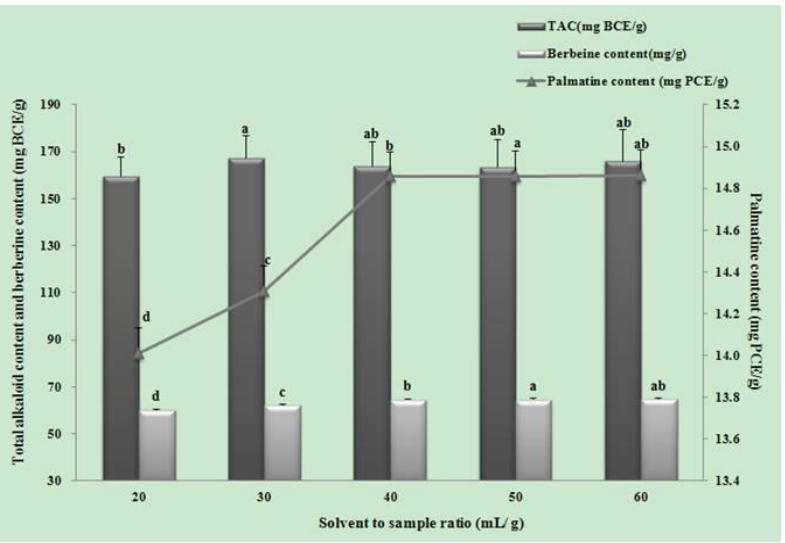

Figure 4. The effect of solvent to sample ratio on alkaloid extraction from rhizoma coptidis.

\subsection{Optimization of process variables}

The BBD matrices were generated based on our previous study, and a phosphoric acid concentration of $0.3 \%$, an extraction time of $4 \mathrm{~h}$, and a solvent to sample ratio of $50 \mathrm{~mL} / \mathrm{g}$ were set as the central points shown in Table 1. All 15 test runs in coded and un-coded forms and the results for the responses under the test runs are summarized in Table 1. 
Table 1. Box Behnken design (BBD) matrices with three levels and three variables, and analytical results for the dependent responses from rhizome coptidis.

\begin{tabular}{lcccccc}
\hline \multirow{5}{*}{ Run } & \multicolumn{3}{c}{ Process variables } & \multicolumn{3}{c}{ Analytical results } \\
\cline { 2 - 6 } no. & $\begin{array}{c}\mathrm{H}_{3} \mathrm{PO}_{4} \text { conc. } \\
(\%)\end{array}$ & ET (h) & $\mathrm{SSR}(\mathrm{mg} / \mathrm{L})$ & $\begin{array}{c}\mathrm{TAC}^{\mathrm{a})} \\
(\mathrm{mg} \mathrm{BCE} / \mathrm{g})\end{array}$ & $\begin{array}{c}\mathrm{BC}^{\mathrm{a})} \\
(\mathrm{mg} \mathrm{BCE} / \mathrm{g})\end{array}$ & $\begin{array}{c}\left.\mathrm{PC}^{\mathrm{b}}\right) \\
(\mathrm{mg} \mathrm{PCE} / \mathrm{g})\end{array}$ \\
\hline 1 & $0.1(-1)$ & $2(-1)$ & $50(0)$ & 179.113 & 54.737 & 12.566 \\
2 & $0.1(-1)$ & $6(+1)$ & $50(0)$ & 186.290 & 61.167 & 14.230 \\
3 & $0.5(+1)$ & $2(-1)$ & $50(0)$ & 195.645 & 64.487 & 14.844 \\
4 & $0.5(+1)$ & $6(+1)$ & $50(0)$ & 199.919 & 69.273 & 15.223 \\
5 & $0.3(0)$ & $2(-1)$ & $40(-1)$ & 190.161 & 63.493 & 14.733 \\
6 & $0.3(0)$ & $2(-1)$ & $60(+1)$ & 197.903 & 62.767 & 14.379 \\
7 & $0.3(0)$ & $6(+1)$ & $40(-1)$ & 183.952 & 65.102 & 14.854 \\
8 & $0.3(0)$ & $6(+1)$ & $60(+1)$ & 195.968 & 69.563 & 15.061 \\
9 & $0.1(-1)$ & $4(0)$ & $40(-1)$ & 165.565 & 55.237 & 12.912 \\
10 & $0.5(+1)$ & $4(0)$ & $40(-1)$ & 192.177 & 63.203 & 14.435 \\
11 & $0.1(-1)$ & $4(0)$ & $60(+1)$ & 186.774 & 61.837 & 13.361 \\
12 & $0.5(+1)$ & $4(0)$ & $60(+1)$ & 190.645 & 62.717 & 14.507 \\
13 & $0.3(0)$ & $4(0)$ & $50(0)$ & 209.306 & 70.728 & 16.242 \\
14 & $0.3(0)$ & $4(0)$ & $50(0)$ & 211.774 & 71.799 & 16.155 \\
15 & $0.3(0)$ & $4(0)$ & $50(0)$ & 212.194 & 72.096 & 16.418 \\
\hline
\end{tabular}

${ }^{\mathrm{a}}$ Results are expressed as mg berberine chloride equivalent/g of dry Rhizome coptidis.

${ }^{\mathrm{b}}$ Results are expressed as mg palmatine chloride equivalent/g of dry Rhizome coptidis.

\subsubsection{Model fitting}

The statistical significances of the second order polynomial models for dependent responses were evaluated by analysis of variance (ANOVA) and are summarized in Table 2. The sum of the squares (SS) of the quadratic model was analyzed, and the results (Table 2) showed that the models for TAC, BC, and PC had good significance, and the linear and quadratic effects of the response models were significant, but no significance of the cross product was observed. Moreover, the fit of the response models was checked by the coefficient of $R^{2}$ and adj- $R^{2}$ as well as pred- $R^{2}$. The $R^{2}$ coefficient indicates how well the model fits the data, and the closer $\mathrm{R}^{2}$ is to 1 , the stronger the model and the better it predicts the response, while an $\mathrm{R}^{2}$ value closer to 0 indicates the regression line does not fit the data very well (15). In this case, the values for the $\mathrm{R}^{2}$ coefficients for TAC, BC, and PC were $97.60 \%, 96.83 \%$, and $98.16 \%$, respectively, which suggest that most of the variables were well described by the response models. In addition, adj- $\mathrm{R}^{2}$ and pred- $\mathrm{R}^{2}$ are also important parameters to check adequate precision, and the adj- $R^{2}$ value is a modification of $R^{2}$, while 
the pred- $\mathrm{R}^{2}$ is used to indicate how well the model predicts responses for new observations. The coefficient of adj- $R^{2}$ and pred- $R^{2}$ coefficients were also high confirming that the fitted models for the responses did not contain any insignificant terms. In addition, the insignificant lack of fit as well as relatively low values for the coefficient of variation (CV) shown in Table 2 indicates good precision and reliability of the fitted models for the dependent responses.

Table 2. Analysis of variance (ANOVA) and fit statistics for the response models for the total alkaloid content, berberine content, and palmatine content in the rhizome coptidis extracts

\begin{tabular}{llllllll}
\hline \multirow{2}{*}{ Source } & \multirow{2}{*}{ DF } & \multicolumn{2}{c}{ Total alkaloid content } & \multicolumn{2}{c}{ Berberine content } & \multicolumn{2}{c}{ Palmatine content } \\
\cline { 2 - 8 } & & SS & F value & SS & F value & SS & F value \\
\hline Model & 9 & 2143.682 & $22.554^{* *}$ & 393.828 & $16.989^{* *}$ & 17.519 & $29.567^{* *}$ \\
(Linear) & 13 & 655.469 & $20.660^{* *}$ & 149.373 & $19.331^{* *}$ & 5.44 & $27.545^{* *}$ \\
(Quadratic) & 3 & 1355.251 & $42.716^{* *}$ & 224.5 & $29.054^{* *}$ & 11.55 & $58.488^{* *}$ \\
(Cross product) & 3 & 135.962 & 4.285 & 19.955 & 2.582 & 0.527 & 2.668 \\
Residual & 5 & 52.879 & & 12.878 & & 0.329 & \\
(Lack of fit) & 3 & 48.009 & 6.593 & 11.843 & 7.624 & 0.293 & 5.446 \\
(Pure error) & 2 & 4.869 & & 1.036 & & 0.004 & \\
$\mathrm{R}^{2}$ & & $97.60 \%$ & & $96.83 \%$ & & $98.16 \%$ & \\
Adj- $\mathrm{R}^{2}$ & & $97.23 \%$ & & $95.01 \%$ & & $97.42 \%$ & \\
Pred- $\mathrm{R}^{2}$ & & $93.27 \%$ & & $91.13 \%$ & & $94.84 \%$ & \\
CV & 1.68 & & 2.49 & & 1.75 & \\
\hline
\end{tabular}

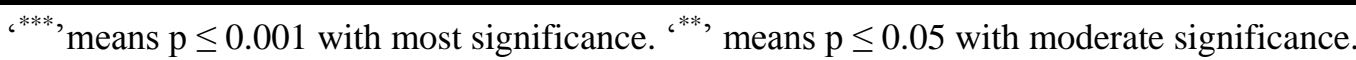

By applying multiple regression analysis to the experimental data, the BBD matrices were fitted into a second order polynomial equation. The significance of each coefficient was determined by t-values, which are listed in Table 3. Thus, equations neglecting insignificant terms for responses are listed below:

$Y_{\mathrm{TAC}}=211.09+7.5805 * A C+4.93 * S S R-14.53 * A C * A C-5.6 * A C * S S R-6.32 * E T * E T-12.77 * S S R * S S R$

$Y_{\mathrm{BC}}=71.54+3.34 * A C+2.45 * E T+1.23 * S S R-6.80 * A C * A C-1.77 * A C * S S R-2.32 * E T * E T-3.99 * S S R * S S R$

$Y_{\mathrm{PC}}=16.27+0.74 * A C+0.36 * E T-1.50 * A C^{*} A C-0.32 * A C^{*} E T-0.55^{*} E T^{*} E T-0.96 * S S R^{*} S S R$

where all equations are presented in coded levels and AC, ET, and SSR are the abbreviations for acid (phosphoric acid) concentration, extraction time, and solvent to sample ratio, respectively. 
Table 3. Effect estimates for the polynomial response models for the total alkaloid content, berberine content, and palmatine content in the rhizome coptidis extracts

\begin{tabular}{|c|c|c|c|c|c|c|}
\hline \multirow{2}{*}{ Term } & \multicolumn{2}{|c|}{ Total alkaloid content } & \multicolumn{2}{|c|}{ Berberine content } & \multicolumn{2}{|c|}{ Palmatine content } \\
\hline & Estimate & t- value & Estimate & t- value & Estimate & t- value \\
\hline $\mathrm{AC}^{\mathrm{a})}$ & 7.580 & $6.593 * *$ & 3.338 & $5.882 * *$ & 0.743 & $8.185^{* *}$ \\
\hline $\mathrm{ET}^{\mathrm{b})}$ & 0.413 & 0.360 & 2.453 & $4.322^{* *}$ & 0.356 & $3.922^{* *}$ \\
\hline $\mathrm{SSR}^{\mathrm{c})}$ & 4.929 & $4.287 * *$ & 1.231 & 2.170 & 0.047 & 0.515 \\
\hline $\mathrm{AC} * \mathrm{AC}$ & -14.528 & $-8.584 * *$ & -6.804 & $-8.146 * *$ & -1.504 & $-11.267 * * *$ \\
\hline $\mathrm{AC} * \mathrm{ET}$ & -0.726 & -0.446 & -0.411 & -0.512 & -0.321 & -2.504 \\
\hline $\mathrm{AC} * \mathrm{SSR}$ & -5.689 & $-3.496 * *$ & -1.772 & -2.208 & -0.094 & -0.735 \\
\hline ET*ET & -6.322 & $-3.735 * *$ & -2.321 & $-2.779 * *$ & -0.551 & $-4.130 * *$ \\
\hline $\mathrm{ET}^{*} \mathrm{SSR}$ & 1.068 & 0.657 & 1.297 & 1.616 & 0.140 & 1.093 \\
\hline SSR *SSR & -12.773 & $-7.547 * *$ & -3.989 & $-4.776 * *$ & -0.963 & $-7.215 * *$ \\
\hline
\end{tabular}

${ }^{\text {a) }}$ Acid $\left(\mathrm{H}_{3} \mathrm{PO}_{4}\right)$ concentration ${ }^{\text {b) }}$ Extraction time ${ }^{\mathrm{c})}$ Solvent to sample ratio

‘***'means $\mathrm{p} \leq 0.001$ with most significance, and ${ }^{* * *}$ means $\mathrm{p} \leq 0.05$ with moderate significance.

\subsubsection{Analysis of the response surface plots}

Based on Eq. (3) - (5), 3-dimensional surface plots and 2-dimensional contour plots were constructed to simulate the interaction of every two variables on the responses and are shown in Figure 5 (a-i). The surface plots for the responses showed good quadratic effects, which confirmed the high significance of the quadratic terms for the responses in Table 3. The critical points for all dependent responses were verified to be maximal within the tested region. Figure 5a-c shows the influence of the process variables on TAC, revealing that the extraction time had an insignificant effect on the TAC yield (Figure 5a, 5c), while the TAC yield increased dramatically with an increase in the phosphoric acid concentration and solvent to sample ratio shown in Figure 5b, and the maximal TAC yield could be obtained around a solvent to sample ratio of $52 \mathrm{~mL} / \mathrm{g}$ and a phosphoric acid concentration of $0.34 \%$ as shown in Figure 5b. The phosphoric acid concentration and extraction time were identified as critical variables for the $\mathrm{BC}$ extraction with significance less than 0.05 (Table 3) while the solvent and sample ratio was found to be insignificant. Based on the response surface plot of Figure 5e and 5f, a low phosphoric acid concentration of around $0.34 \%$ could lead to a maximal BC yield, however, a high concentration phosphoric acid had a negative effect on the $\mathrm{BC}$ yield. An extraction time of $5 \mathrm{~h}$ was found to be appropriate for the $\mathrm{BC}$ extraction, however, no further increase in the $\mathrm{BC}$ yield was observed beyond $5 \mathrm{~h}$. Figure $5 \mathrm{~h}$ and $5 \mathrm{i}$ revealed that the solvent to sample ratio had a slight influence on the PC yield confirmed by the insignificance of the solvent to sample ratio in Table 3. There was a good quadratic effect for the PC model, but no interaction was found. An extraction time of approximate $4.5 \mathrm{~h}$ and a phosphoric acid concentration around $0.34 \%$ could 
achieve a maximal PC yield as shown in Figure 5j.
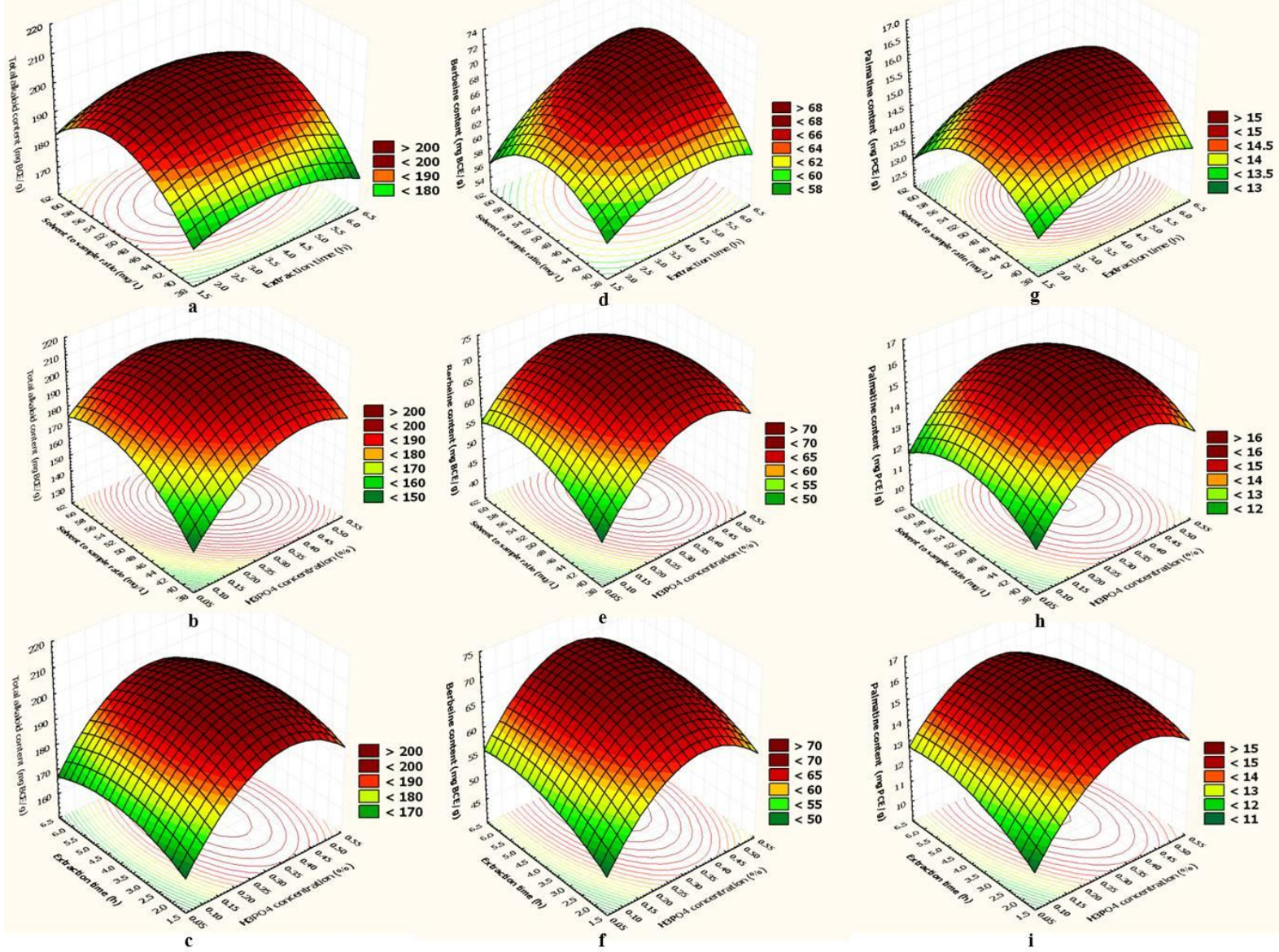

Figure 5. Response surface plots and contour plots for total alkaloid content (a-c), berberine content (d-f), and palmatine content (g-i). (a, d, g) varying the solvent to sample ratios and extraction times; (b, $\mathrm{e}, \mathrm{h}$ ) varying the solvent to sample ratios and phosphoric acid concentrations; (c, f, i) varying the extraction times and phosphoric acid concentrations.

\subsubsection{Optimization of the process variables and verification of the prediction}

Although the critical points for all responses were verified to be maximal within our tested regions, and the optimal conditions for each response could be obtained through canonical analysis, in order to predict the optimal conditions for the three responses simultaneously, the contour plots were overlapped to find the proper region that could yield satisfactory responses. However, the application of an overlapped contour plot has a constraint that only two variables can be included, and one variable was fixed at an appropriate level. It was found from the above plot analysis that a phosphoric acid concentration of $0.34 \%$ could get maximal responses for TAC, BC, and PC. Therefore, the superimposed contour plot (Figure .6) showing the effect of the extraction time and solvent to sample ratio were overlapped while the phosphoric acid concentration was kept constant at $0.34 \%$. Finally, the obtained optimal conditions were $0.34 \%$ 
phosphoric acid, $5.00 \mathrm{~h}$ extraction time, and $51.45 \mathrm{~mL} / \mathrm{g}$ solvent to sample ratio, which could be attributed to the estimated maximal values of $208.30 \mathrm{mg} \mathrm{BCE} / \mathrm{g}$ for TAC, 72.62 $\mathrm{mg} \mathrm{BCE} / \mathrm{g}$ for $\mathrm{BC}$, and $15.80 \mathrm{mg} \mathrm{PCE} / \mathrm{g}$ for PC. In order to check the validity of the predicted results, verification experiments were carried out under the estimated optimal conditions. As shown in Table 4, the observed values for TAC, BC, and PC were $207.10 \mathrm{mg} \mathrm{BCE} / \mathrm{g}, 72.48 \mathrm{mg} \mathrm{BCE} / \mathrm{g}$, and $15.77 \mathrm{mg} \mathrm{PCE} / \mathrm{g}$, respectively, and no significant difference with the estimated values was observed according to the Duncan-test results. Thus, it was concluded that the fitted models are valid and adequate to predict the yield of the alkaloid extraction process within the range of the experimental variables.

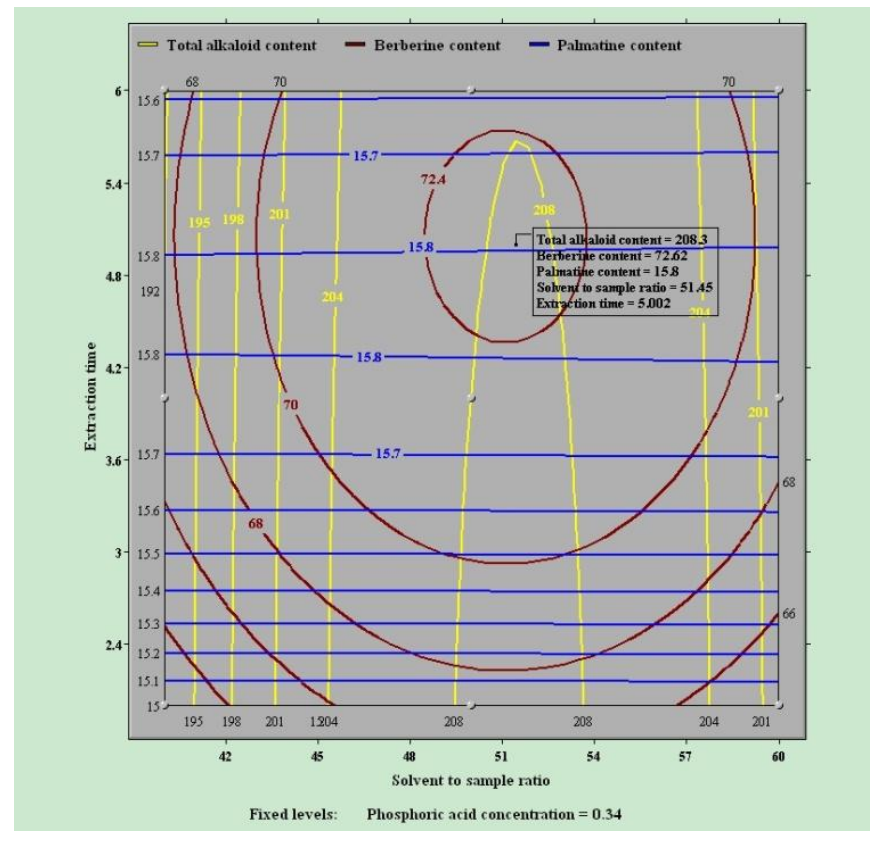

Figure 6. Overlapped contour plots for simultaneous optimization of total alkaloid content, berberine content, and palmatine content in acid maceration extraction. The plot shows the effects of the extraction time and solvent to sample ratio while the phosphoric acid concentration was kept at $0.34 \%$.

Table 4. Predicted optimal extraction conditions, and comparison of estimated and observed values for dependent responses at those conditions

\begin{tabular}{ccccccccc}
\hline \multicolumn{2}{c}{ Optimal conditions } & \multicolumn{2}{c}{ TAC $(\mathrm{mg} \mathrm{BCE} / \mathrm{g})$} & \multicolumn{2}{c}{ BC $(\mathrm{mg} \mathrm{BCE} / \mathrm{g})$} & \multicolumn{2}{c}{ PC $(\mathrm{mg} \mathrm{PCE} / \mathrm{g})$} \\
\hline AC & ET & SSR & Obs. & Est. & Obs. & Est. & Obs. & Est. \\
$(\%)$ & $(\mathrm{h})$ & $(\mathrm{mL} / \mathrm{g})$ & value & value & value & value & value & value \\
\hline 0.34 & 5.00 & 51.45 & 207.10 & 208.30 & 72.48 & 72.62 & 15.77 & 15.80 \\
\hline
\end{tabular}

\subsection{Comparison with different extraction methods}

Other commonly used conventional extraction methods such as heating reflux extraction and soxhlet extraction were employed as a comparative study for the alkaloids extraction from rhizome coptidis. The experimental conditions together with the analysis results for TAC, BC, and PC with the different extraction methods are summarized in Table 5. The results showed acid-assisted extraction without heating for $5 \mathrm{~h}$ with $0.34 \%$ phosphoric acid solution gave superior results for total alkaloid extraction (about 1.5 times more than heating reflux and 1.1 times more than soxhlet), while the berberine content in the acid-assisted extracts was 1.1 times more than for reflux and soxhlet extraction, and the palmatine content 
extracted using the different extraction methods showed no significant difference. Besides those conventional extraction techniques, other advanced extraction technologies have been applied for alkaloid extraction from rhizome coptidis as well. Lee et al. [12] carried out the extraction of berberine and palmatine from rhizome coptidis using narrow-bore high performance liquid chromatography, and a berberine content of $5.0 \%$ (approximately $50 \mathrm{mg} / \mathrm{g}$ ) and a palmatine content of $2.1 \%$ (approximately 21 $\mathrm{mg} / \mathrm{g}$ ) were obtained. Ong and Len [16] reported on the application of pressurized hot water as an extraction medium for the extraction of alkaloids from rhizome coptidis and $62.72 \mathrm{mg} / \mathrm{g}$ of berberine were detected. Acid-assisted extraction is a common used technique in alkaloid extraction, which uses a low concentration acid solution to combine with free base organic alkaloids with high molecular weights thus transforming them into inorganic alkaloid salts with low molecular weight so that the solubility of the alkaloids could be increased and thus, improving the yield of the alkaloids [17]. In addition, there is no heating required for the extraction process. Thus, many temperature sensitive compounds can be retained and the operation of the acid-assisted extraction is simple, secure and economic. Moreover, this study firstly discovered that phosphoric acid was more suitable than sulfuric acid which has been commonly used for alkaloid extraction in laboratory work. Since phosphoric acid is more secure and has been widely used in the food industry [18], it is proposed that acid-assisted extraction with low concentration phosphoric acid can be considered as an alternative choice for large scale production of alkaloids.

Table 5. Comparison of different methods for the extraction of total alkaloid content (TAC), berberine content (BC), and palmatine content (PC) from rhizome coptidis

\begin{tabular}{lccccccc}
\hline \multirow{2}{*}{$\begin{array}{l}\text { Extraction } \\
\text { methods }\end{array}$} & \multicolumn{3}{c}{ Extraction conditions } & \multicolumn{3}{c}{ Observed values for responses } \\
\cline { 2 - 8 } & Medium & ET $(\mathrm{h})$ & $\begin{array}{c}\text { SSR } \\
(\mathrm{mL} / \mathrm{g})\end{array}$ & $\begin{array}{c}\text { Temp. } \\
\left({ }^{\circ} \mathrm{C}\right)\end{array}$ & $\begin{array}{c}\text { TAC } \\
(\mathrm{mg} \mathrm{BCE} / \mathrm{g})\end{array}$ & $\begin{array}{c}\mathrm{BC} \\
(\mathrm{mg} \mathrm{BCE} / \mathrm{g})\end{array}$ & $\begin{array}{c}\mathrm{PC} \\
(\mathrm{mg} \text { PCE/g) }\end{array}$ \\
\hline $\begin{array}{l}\text { Acid- } \\
\text { assisted }\end{array}$ & $\begin{array}{l}0.34 \% \\
\mathrm{H}_{3} \mathrm{PO}_{4}\end{array}$ & 5.00 & 51.45 & 25 & $207.10 \pm 2.54$ & $72.48 \pm 1.27$ & $15.77 \pm 0.15$ \\
$\begin{array}{l}\text { Heating } \\
\text { reflux }\end{array}$ & $\begin{array}{l}50 \% \\
\text { ethanol }\end{array}$ & 4.00 & 35.00 & 70 & $140.91 \pm 3.01$ & $67.08 \pm 2.95$ & $16.07 \pm 0.24$ \\
Soxhlet & $\begin{array}{l}50 \% \\
\text { ethanol }\end{array}$ & 4.00 & 50.00 & 70 & $189.14 \pm 3.99$ & $65.52 \pm 1.81$ & $16.11 \pm 0.22$ \\
\hline
\end{tabular}

\section{Conclusions}

In the present study, the effects of different acid types, extraction time, acid concentration, and solvent to sample ratio were investigated, and phosphoric acid showed the best extraction performance compared with the other four acids tested. Response surface methodology was applied to optimize the process variables and the optimal conditions of $0.34 \%$ phosphoric acid, $5.00 \mathrm{~h}$, and $51.45 \mathrm{~mL} / \mathrm{g}$ were determined 
with the overlapped contour plot. No significant difference was found between the estimated values and observed values, which verified that the fitted model was valid and reliable within the range of variables. Acid-assisted extraction is therefore proven to be a good option for alkaloid extraction with low cost, high efficiency, and easy operation.

\section{Acknowledgement}

This research was supported by Kyungpook National University Research Fund, 2012

\section{References}

1) H. Wagner, Chromatographic fingerprint analysis of herbal medicines. 2nd ed. pp. 301.Springer. New York, U.S.A (2011).

2) J. H. Chen, F. M. Wang, J. Liu, F. S. C. Lee, X. R. Wang, H. H. Yang, Anal. Chim. Acta, 613, 184-195 (2008).

3) P. H. Xu, Y. Gao, X. Q. Zhang, L. Zhang, K. Xu, Lishizhen Med. Mater. Med. Res,. 18, 3079-3080 (2007).

4) Y. J. Surh, Nat. Rev. Cancer, 3, 768-780 (2003).

5) W. Kong, J. Wei, P. Abidi, M. Lin, S. Inaba, C. Li, Y.L. Wang, Z. Z. Wang, S. Y. Si, H. N. Pan, S. K. Wang, J. D. Wu, Y. Wang, Z. R. Li, J. W. Liu, J. D. Jiang, Nat. Med., 10, 1344-1351 (2004).

6) C. L. Kuo, C. W. Chi, T. Y. Liu, Cancer Lett., 203, 127-137 (2004).

7) K. Hayashi, K. Minoda, Y. Nagaoka, T. Hayashi, S. Uesato, Bioorg. Med. Chem. Lett., 17, 1562-1564 (2007).

8) E. S. Ong, S. O. Woo, Y. L. Yong, J. Chromatogr. A, 904, 57-64 (2000).

9) B. Liu, W. J. Li, Y. L. Chang, W. H. Dong, L. Ni, J. Pharm. Biomed. Anal., 41, 1056-1060 (2005).

10) Q. G. Zhao, S. T. Wu, Y. Wang, J. Xie, X. H. Xiao, C. S. He, Lishizhen Med. Mater. Med. Res., 12, 974-976 (2001).

11) X. Ye, Y. Feng, Y. Tong, K. M. Ng, S.Tsao, G. K. Lau, C. Sze, Y. Zhang, J. Tang, J. Shen, S. Kobayashi, J. Ethnopharmacol., 124, 130-136 (2009).

12) H. S. Lee, Y. E. Eom, D. O. Eom, J. Pharm. Biomed. Anal., 21, 59-63 (1999).

13) B. L. Ma, Y. M. Ma, R. Shi, T. M. Wang, N. Zhang, C. H. Wang, Y. Yang, J. Ethnopharmacol., 128, 357-364 (2010).

14) F. P. Wu, H. J. Yang, Y. Yang, Sci. Tech. Inf., 25, 168-170 (2009).

15) R. H. Myers, Response surface methodology: process and product optimization using designed experiments. 2nd ed. pp. 219-264. New Jersey: Wiley, New York, U.S.A (2009).

16) E.S. Ong, S.M. Len, Anal. Chim. Acta, 482, 81-89 (2003).

17) R. Marek, P. Seckarova, D. Hulova, J. Marek, J. Dostal, V. Sklena, J. Nat. Prod. 66, 481-486 (2003).

18) A. G. J. Voragen, Trends Food Sci. Tech., 9, 328-335 (1998). 